\title{
Soda-Lime Glass with Gradient of Refraction Index (GRIN)
}

\author{
J. R. B. Paião, F. Pereira, S. Watanabe \\ Instituto de Física, Universidade de São Paulo, \\ CP 66318, CEP 05315-970, São Paulo, SP, Brazil
}

Received on 18 August, 2000

\begin{abstract}
In a soda-lime glass provided by Companhia Vidraria Santa Marina, subsidiary of French SaintGobain, we induced a gradient of refraction of index (GRIN) by exchange of $\mathrm{Na}^{+}$in glass by $\mathrm{Li}^{+}$ at $550^{\circ} \mathrm{C}$ for $12,24,36$ and 48 hours and varying bath temperature at $525^{\circ} \mathrm{C}, 550^{\circ} \mathrm{C}, 575^{\circ} \mathrm{C}$ and $600^{\circ} \mathrm{C}$ for fixed time of 48 hours. $\Delta \mathrm{n}=0.0107 \pm 0.0005$ and GRIN depth of about $2.4 \mathrm{~mm}$ were obtained for the ion exchange at $550^{\circ} \mathrm{C}$ for 48 hours. The GRIN profile was fitted with $\operatorname{erf} c(x)$ function and then obtained the diffusion coefficient $D=(1.6 \pm 0.3) \cdot 10^{-6} \mathrm{~mm}^{2} / \mathrm{s}$.
\end{abstract}

\section{Introduction}

The so called optical glasses have been traditionally homogeneous. During last thirty years, glasses having index of refraction varying with spatial coordinates have been introduced. Ion exchange in glasses was discussed by Garfinkel [1] and Doremus [2] in 1968 and 1969, respectively. Problems concerning optics of GRIN glasses have been treated by Sands [3, 4], Moore and Sands [5], and Kapron [6] in the early 70's. Several techniques have been used for manufacturing GRIN glasses such as neutron irradiation, chemical vapor deposition, polymerization techniques, ion exchange, ion stuffing and sol-gel process. CVD technique has been used to produce GRIN fibers for telecommunications [7]. Ion exchange is probably the most widely used technique due to its relatively simple one compared to other processes. Ion stuffing consists in using a special glass that when heated, its phases separate [8]. One of these phases is dissolved in an acid leaving a porous glass, then it is stuffed with ions or molecules in such a way that a gradient composition is produced. Sol gel process can be used in fabricating GRIN rods with large geometry [9]. The gradient in the refractive index can be produced in the radial, axial or spherically symmetrical direction. Such GRIN elements have been used in copiers, facsimiles, endoscopes, etc. Several kinds of base glasses have been investigated. For exchange, $\mathrm{Li}^{+}, \mathrm{Na}^{+} \mathrm{K}^{+}, \mathrm{Tl}^{+}$, $\mathrm{Ag}^{+}$ions are frequently used [10].

\section{Experiments and results}

Samples of soda-lime glass fabricated by Comp. Vidraria Santa Marina in S. Paulo, was used in the present work. Its composition is: $72 \mathrm{SiO}_{2}-9 \mathrm{CaO}-$
$13 \mathrm{Na}_{2} \mathrm{O}-4 \mathrm{MgO}-\mathrm{Al}_{2} \mathrm{O}_{3}$ with small amounts of $\mathrm{Fe}_{2} \mathrm{O}_{3}$, $\mathrm{TiO}_{2}$ and $\mathrm{K}_{2} \mathrm{O}$ (these three compounds totaling about $1 \%$ weight are also found). The refractive index of this glass was found to be $n_{o}=1.5213 \pm 0.0005$. The ion exchange method was used for inducing the gradient of refractive index. Initially, we used a bath of molten of $\mathrm{LiCl}$ for the exchange $\mathrm{Li}^{+} \leftrightarrow \mathrm{Na}^{+}$of the glass. The melting point of $\mathrm{LiCl}$ is $600^{\circ} \mathrm{C}$, and since for soda-lime glass $\mathrm{T}_{g} \sim 610^{\circ} \mathrm{C}$, immersing the glass into $\mathrm{LiCl}$ melt the glass devitrified strongly. We then followed Kindred et al. experiments [10], in which to lower the bath temperature, $\mathrm{CaCl}_{2}$ was mixed. They used an eutetic mixture of $60 \mathrm{CaCl}_{2}-40 \mathrm{LiCl}$ with melting temperature of $496^{\circ} \mathrm{C}$. In the present work the samples were kept immersed in such a bath at $550^{\circ} \mathrm{C}$ and varying time of ion exchange, Fig. 1, and varying bath temperature for

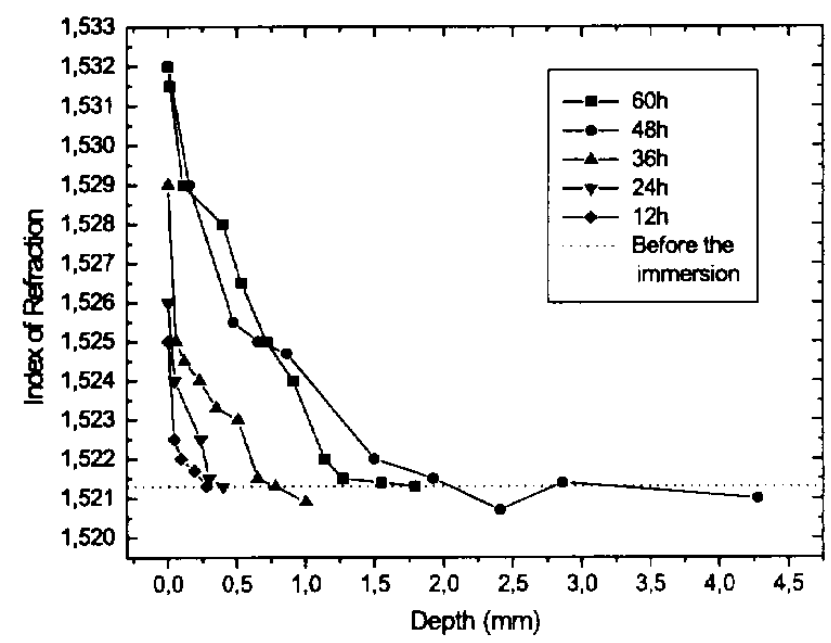

Figure 1. GRIN profiles for different times of ion exchange $\left(550^{\circ} \mathrm{C}\right)$. 
fixed 48 hours exchange time, Fig. 2. After ion exchange process the samples were cooled at room temperature. The glass presented crystallization characterized by milky colour. A surface layer was removed to eliminate devitrified portion. X-ray diffractogram indicates that the remaining part of the glass is amorphous. The measurement of variation of the refractive index $n$ with depth was carried out removing successive layers and measuring $n$ each time.

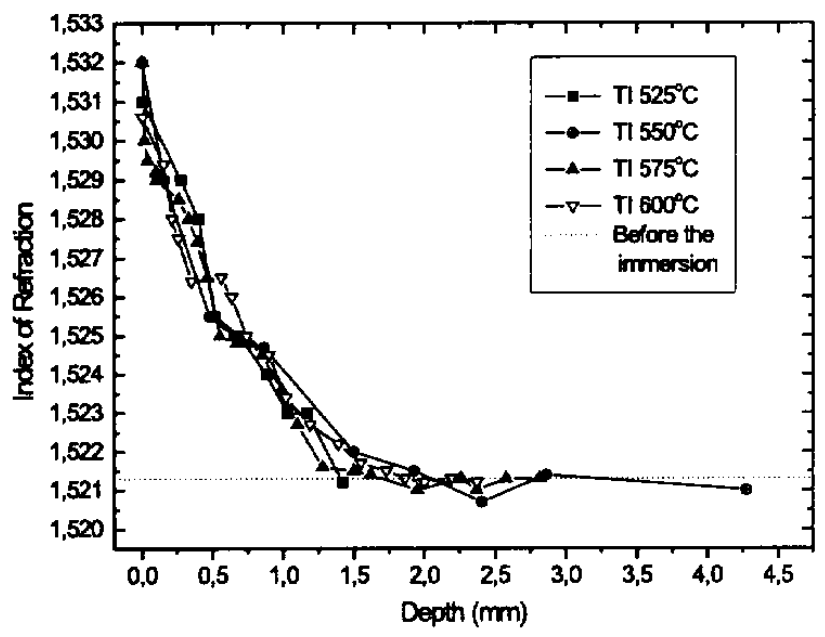

Figure 2. GRIN profiles for different temperatures for fixed time of exchange $(48 \mathrm{~h})$.

\section{Ionic diffusion and GRIN}

Fick's laws describe the ions diffusion in a solid. Denoting by $C(x, t)$, the concentration of diffusing species at depth $x$ and at instant t, by $D(T)$ the diffusion constant at temperature $T$, the solution of Fick's laws for $D(T)$ constant at $T$ is given by:

$$
C(x, t)=C_{0} \cdot \operatorname{erfc}\left(\frac{x}{\sqrt{4 D t}}\right)
$$

where

$$
\begin{aligned}
& C(x=0, t \geq 0)=C_{0} \\
& C(x>0, t=0)=0
\end{aligned}
$$

The refractive index of a GRIN glass is then dependent on $C(x, t)[11]$ :

$$
n(x, t)=n_{0}+\Delta n \cdot \operatorname{erfc}\left(\frac{x}{\sqrt{4 D t}}\right)
$$

Fig. 3 presents the GRIN profile for 48 hours and $550^{\circ} \mathrm{C}$ with depth of about $1.95 \pm 0.05 \mathrm{~mm}$.

The full curve in Fig. 3 is the best fit of experimental data, using the equation 3 . The refractive index at the surface $n_{0}=1.5210 \pm 0.0005$, the maximum variation of $n, \Delta \mathrm{n}=0.0107 \pm 0.0005$ and the diffusion coefficient $\mathrm{D}=(1.6 \pm 0.3) \cdot 10^{-6} \mathrm{~mm}^{2} / \mathrm{s}$ were obtained from this best fit.

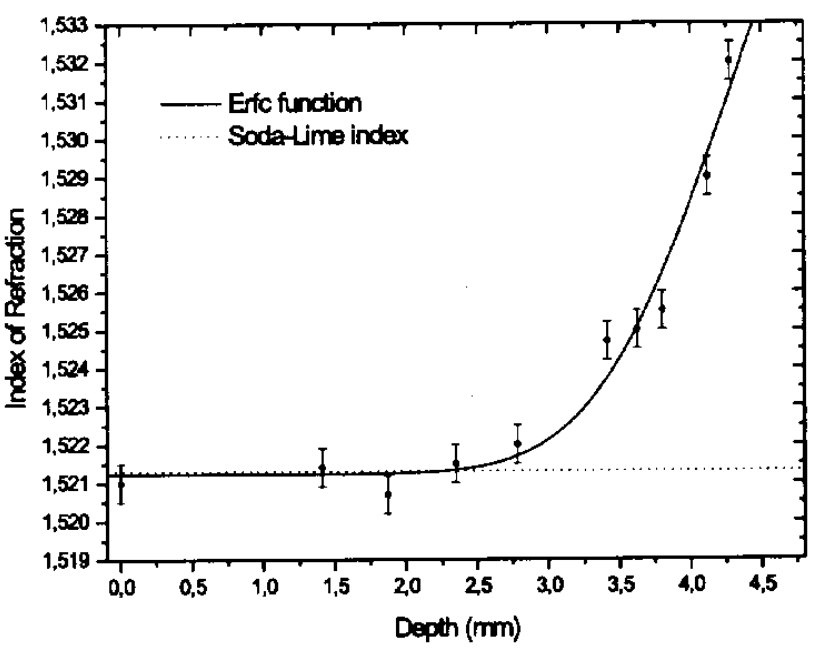

Figure 3. Axial GRIN profile produced by $\mathrm{Li}^{+}$for $\mathrm{Na}^{+}$ exchange in a soda-lime glass for 48 hours and $550 \mathrm{C}^{\circ}$.

\section{Ray tracing}

In Fig. 4, a laser beam is incident on a slab of GRIN glass with thickness $L$. $\alpha$ being the angle of incidence of laser beam and $\theta_{o}$ the angle of refraction at the entrance surface, after reaching GRIN region, at any point $x$, according to Snell's law:

$$
n_{\text {air }} \cdot \sin \alpha=n_{0} \cdot \sin \theta_{0}=n(x) \cdot \sin \theta(x)
$$

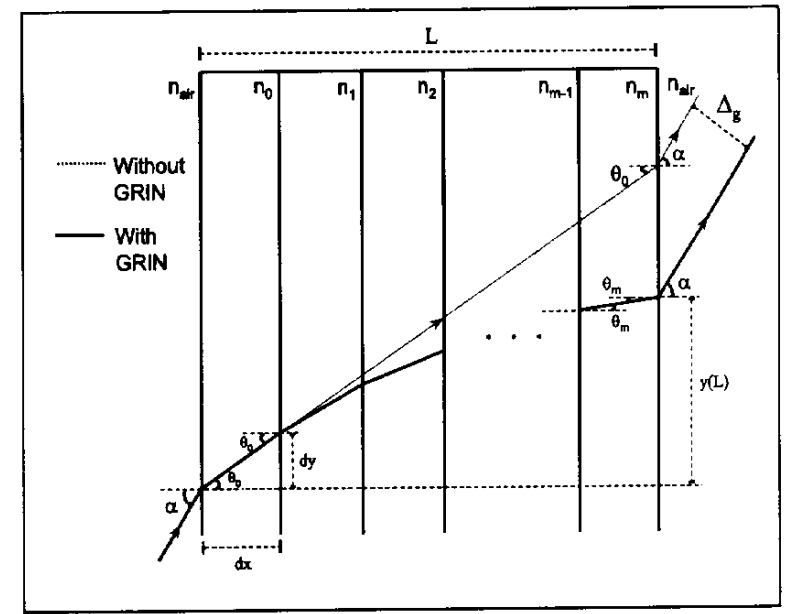

Figure 4. Laser beam incident on a slab of GRIN glass.

where $x$ is measured from beginning of GRIN and perpendicular to slab surface. The ray emerges at an angle $\alpha$ with respect to the normal to glass surface. Since in an homogeneous glass with refractive index $n_{0}$, the ray 
entering under angle $\alpha$ emerges also forming an angle $\alpha$, the effect of GRIN is to produce a displacement $\Delta_{g}$ of emergent ray compared to emergent ray from a glass without GRIN. A numerical calculation using the equation 4 produced for GRIN glass obtained here, a value of about $\Delta_{g} \sim 0.00202 \mathrm{~mm}$ for $\alpha \sim 57^{\circ}$. Experimentally, this is a value too small to be measured due to the laser beam diameter. The table 1 lists values of $\Delta_{g}$ for $\alpha$ between 30 and $80^{\circ}$. The Fig. 5 shows the variation of $\Delta_{g}$ as function of $\alpha$.

Table 1. $\Delta_{g}$ as function of the incidence angle $\alpha$.

\begin{tabular}{|c|c|}
\hline$\alpha$ (degrees) & $\Delta_{g}(\mathrm{~mm})$ \\
\hline \hline 30 & 0.00132 \\
\hline 36 & 0.00156 \\
\hline 42 & 0.00177 \\
\hline 45 & 0.00185 \\
\hline 51 & 0.00198 \\
\hline 54 & 0.00201 \\
\hline 57 & 0.00202 \\
\hline 60 & 0.00200 \\
\hline 63 & 0.00195 \\
\hline 69 & 0.00174 \\
\hline 75 & 0.00139 \\
\hline 81 & 0.00090 \\
\hline
\end{tabular}

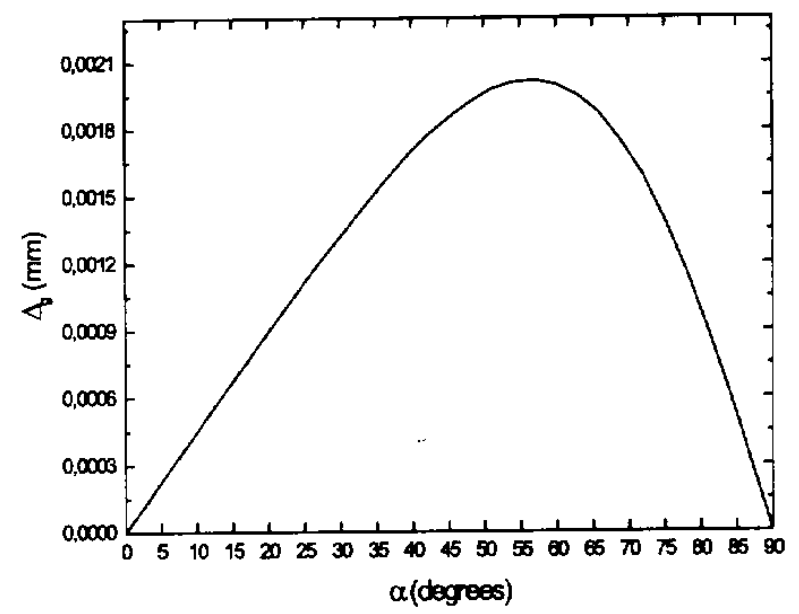

Figure 5. Variation of $\Delta_{g}$ as function of $\alpha$.

\section{Discussion and Conclusion}

According to Kindred [11], in many cases the refraction index is linearly dependent on the concentration. This is the present case. With the exchange $\mathrm{Li}^{+} \leftrightarrow \mathrm{Na}^{+}$, Haun et al. [12] did not fit the the GRIN profile with $\operatorname{erfc}(\mathrm{x})$ as we did. Fig. 1 has shown that both the depth of exchange and the variation $\Delta \mathrm{n}$ of the index of refraction increase with the time of exchange, however, the result shown in Fig. 2 indicated that for fixed time of 48 hours, the depth of exchange and $\Delta \mathrm{n}$ did not change with temperature in the range $525^{\circ} \mathrm{C}$ and $600^{\circ} \mathrm{C}$. This last result is due to the increase in the thickness of crystallized layer. The maximum variation $\Delta \mathrm{n}$ and largest depth of exchange were obtained for time between 48 and 60 hours at $550^{\circ} \mathrm{C}$, as well as for 48 hours at temperature between $550^{\circ} \mathrm{C}$ and $575^{\circ} \mathrm{C}$. For 48 hours at $550^{\circ} \mathrm{C}, \Delta \mathrm{n}=0.0107 \pm 0.0005$ and a depth of $1.95 \pm 0.05$ $\mathrm{mm}$ were obtained. At this temperature a coefficient of diffusion of $\mathrm{Li}^{+}$with value $\mathrm{D}=(1.6 \pm 0.3) \cdot 10^{-6} \mathrm{~mm}^{2} / \mathrm{s}$ was obtained. Meyer-Arendt [13] suggested the use of GRIN glass to eliminate spherical aberration. Grinding and polishing the GRIN glass region a preliminary result showed a lens without spherical aberration.

\section{Acknowledgements}

The authors acknowledge CNPq and FAPESP for financial support. Thanks are due to Eng. Marcos Gibin, Head, Centro Técnico de Elaboração do Vidro, Companhia Santa Marina, for providing us with the samples used in this paper.

\section{References}

[1] M. Garfinkel, J. Phys. Chem. 72, 4175 (1968).

[2] R. H. Doremus and J. Marinsky, in Ion Exchange in Glasses (Marcel Dekker, New York, 1969) p. 5.

[3] J. P. Sands, J. Opt. Soc. Am. 60, 1436 (1970).

[4] J. P. Sands, J. Opt. Soc. Am. 61, 1086 (1971).

[5] D. T. Moore and J. P. Sands, J. Opt. Soc. Am. 61, 1191 (1971).

[6] F. P. Kapron, J. Opt. Soc. Am. 60, 1433 (1970).

[7] M. A. Pickering, R. L. Taylor and D. T. Moore, Appl. Opt. 25, 3364 (1986).

[8] R. K. Morh, J. A. Wilder, P. B. Macedo and P. K. Gupta, in Digest of Topical Meeting on Gradient Index Optical Imaging Systens (Opt. Soc. Am.), Washigton, D. C. (1979).

[9] M. Yamane and S. Noda, J. Ceram. Soc. Japan, 101, $11(1993)$

[10] D. S. Kindred, J. Bentley and D. T. Moore, Appl. Opt. 29, 4036 (1990).

[11] D. S. Kindred, Appl. Opt. 29, 4051 (1990).

[12] N. Haun, D. S. Kindred and D. T. Moore, Appl. Opt. 29, 4056 (1990).

[13] J. R. Meyer-Arendt, in Introduction to Classical and Modern Optics (Prentice Hall, New Jersey, 1995) p. 123. 